\title{
Use of Mobile Health Technologies for Self-tracking Purposes among Seniors: A Comparison to the General Adult Population in Canada
}

\author{
Mirou Jaana \\ University of Ottawa \\ jaana@telfer.uottawa.ca
}

\author{
Guy Paré \\ HEC Montréal \\ guy.pare@hec.ca
}

\begin{abstract}
Based on a national survey of adults investigating digital self-tracking in Canada, this study compares seniors' use of mHealth technologies to the general population, and explores the factors related to their use. Despite significant differences between the two groups on smart technologies and Internet use, a considerable number of seniors in the community use smart phones and digital tablets and are familiar with smart devices/wearables. Yet, only $20 \%$ reported downloading mobile applications (mApps) and $12 \%$ indicated using smart devices/wearables. The majority of mApps downloaded by seniors were health-related; interestingly, their use was sustained over a longer period of time compared to the general population. No significant differences were observed between the two groups with regard to satisfaction with mHealth technologies and intention to continue using them, which were favorable. Leveraging these technologies in partnership with health care providers, and sharing of health/wellbeing data with health professionals, family members or friends remains very limited.
\end{abstract}

\section{Introduction}

Population aging represents a global phenomenon that is associated with increased prevalence of chronic conditions [3, 33, 40]. In 2017, the global number of people aged 60 years and older was 962 million (with 137 million $\geq 80$ years), and it is expected to reach 2.1 billion by 2050 [40]. This leads to an increased demand on health systems for services that are costly and require significant resources [14].

A recent Commonwealth survey of older adults in 11 countries investigated the challenges faced by elderly $\geq 65$ years at the social and health care levels [33, 39]. The results showed that, across all surveyed countries, seniors in general, and the elderly with high need in particular (i.e. multiple chronic conditions / functional challenges), suffer from social isolation, and have high rates of emergency visits and general dissatisfaction with the quality of care they receive [33].

In Canada, we continue to observe longer wait times for various types of services (e.g., doctors, specialists, emergency) compared to other developed countries [8]. In general, Canadians tend to be more frequent users of health services [8], and concerns have been growing about the ability of the public health care system to address the increasing needs of the aging population [7]. This is particularly critical given the high health care spending per capita on seniors and high consumption of services by this group [7].

Mobile health (mHealth) technologies present an opportunity to address the challenges associated with population aging and enables support for seniors in the community. Prior research has examined the potential role of mHealth technologies in providing long-term support for elderly [10, 17, 29], and in monitoring chronic conditions often associated with older age [20, 21, 22, 23, 24, 26, 34]. Self-tracking devices (e.g., smart devices with mobile apps, fitness trackers, blood pressure monitors) have gained interest in recent years in light of their potential for monitoring and motivating individuals to remain healthy $[13,27,28,37]$. Yet, their use remains variable and less widespread among seniors [6], and prior research has reported the risk of health information tracking prompting negative emotions among patients with multiple chronic conditions, and the potential emotional draining on this group [16]. To date, limited information is available on Canadian seniors' attitudes toward and use of mHealth technologies for self-tracking purposes.

The present study, which is part of a larger research on digital health self-tracking [35], addresses this gap and presents the results of a national survey across all provinces in Canada that assessed seniors' familiarity with and use of mHealth technologies which comprise mobile applications (mApps), smart devices and wearables. Specifically, we report findings on the pattern of elderly use of mHealth technologies for selftracking purposes compared to the general population. We also investigate the factors that influence the continued usage of mHealth technologies among 
elderly. To do so, we developed a research model based on the work by Bhattacherjee [2] and Hong et al. [18] and the expectation-confirmation theory [32]. In the present context, this model suggests that an elderly's intention to continue using mHealth technologies is mainly influenced by his or her level of satisfaction. His or her satisfaction level is in turn affected by the extent to which his or her initial expectations toward mHealth technologies are confirmed, in addition to ease of use and perceived usefulness [11]; the latter also have direct links with usage continuance intention [18]. In sum, the present study attempts to answer the following research questions: (1) To what extent do elderly use mHealth technologies to self-track their health? (2) How does such usage compare to the general adult population? (3) What factors influence the continued usage of mHealth technologies among elderly?

\section{Methods}

\subsection{Study Design and Sample}

A cross-sectional survey was conducted to provide answers to our research questions. The questionnaire instrument was administered online to a national sample of 4,109 Canadian residents, who spoke English or French. The sample was selected from a proprietary online panel (AC Nielsen Company), which is considered one of the largest and most representative panels in Canada. In order to ensure representativeness of the overall Canadian adult population, the quota method was applied (age and gender) following a stratification by georgraphic region. Eligible respondents read and approved an informed consent form prior to completing the questionnaire. Ethics approval was granted by the HEC Montréal's research ethics committee. The elderly group included all respondents aged 65 years and older, as opposed to the general population consisting of respondents of age 1864 years.

\subsection{Survey and Data Collection}

The survey instrument consisted of different sections that covered three main areas: 1) demographic characteristics, health status and comorbidities; 2) familiarity with and use of mHealth technologies (i.e. mApps, consumer smart devices/wearables like vital signs monitors, bathroom scales, fitness trackers, intelligent clothing, etc.); and 3) factors influencing the continued use of mHealth technologies. The latter section also assessed satisfaction, ease of use, expectations confirmation, perceived usefulness, and intention to continue using mHealth technologies.

Socio-demographic variables were measured using standardized indicators used in other international surveys $[1,5,15,19]$. These included: gender, age, region, gross family income, education, occupation, and use of mobile phones and digital tablets. Health status was self-rated by respondents on a [1-5] scale (1=poor or fair; 5=very good or excellent), which represents an approach that has been used extensively [4]. And overall, 11 chronic conditions were investigated (e.g., diabetes, high blood pressure, cardiovascular disease, lung or respiratory, cancer, etc.).

Next, we assessed respondents' familiarity with mHealth technologies using a combination of items. A general question measured their familiarity with consumer wearables and smart medical devices using a 5point Likert scale $(1=$ not much at all familiar; 5=extremely familiar). Second, we asked participants to indicate which devices they owned using descriptive terms that referred to a total of 13 devices identified in the literature and available in the Canadian market. When participants indicated owning a specific device or wearable, they were asked to rate on a [1-7] scale (1=once a month or less; $7=$ many times a day) how often they used it in the past three months.

Three self-tracking profiles were identified in this study based on the respondents' indication of their health tracking behavior. Those that regularly tracked one or more aspects of their health or well-being using mHealth technologies including mApps for health, consumer wearables (e.g., fitness trackers), and smart medical devices (e.g., blood pressure monitors) were defined as "digital trackers." Respondents who regularly monitored one or more aspects of their health and well-being using manual tools (i.e. recording the information in writing) were defined as "traditional trackers." All other respondents who did not regularly monitor any aspect of their personal health were considered as "non trackers".

Last, we measured the factors that are likely to influence the continued usage of mHealth technologies. First, measures of perceived usefulness (7 items) and ease of use (4 items) were adapted from Davis [11] and used a 5-point Likert scale (1=strongly disagree; $5=$ strongly agree). We also adapted measures from Bhattacherjee [2] and Hong et al. [18] to assess users' satisfaction (3 items), confirmation of initial expectations (3 items) on a [1-5] Likert scale (1=strongly disagree; 5=strongly agree). The complete survey instrument is available upon request from the second author.

Data collection was done over a period of three weeks in early 2017. Respondents were allowed to access their surveys using a unique identifier/passcode. They were rewarded points (up to CAN \$75) for survey 
completion. Standard options include gift cards and merchandise (e.g., Amazon, iTunes, magazine subscriptions, Starbucks, Wal-Mart, and a variety of restaurant gift cards).

\subsection{Data Analysis}

Data analysis was conducted to explore and better understand the pattern of use of these technologies and self-tracking behaviors by seniors in the community, and in comparison to the general population. Descriptive data analysis was performed to present an overview of the elderly group characteristics and their use of mHealth technologies. Bivariate analyses (t-test for continuous variables and Chi-square for categorical variables) were conducted to assess the differences between the two groups on these variables. Multinomial logistic regression tests were used to compare selftrackers (traditional and digital) and non-trackers, and Pearson correlation tests and partial least squares (PLS) multiple regression analyses were used to analyze users' appreciation of digital self-tracking devices. Data analyses were performed on IBM SPSS Statistics v25 and SmartPLS 2.0.

\section{Results}

\subsection{Sample Characteristics}

The sample consisted of 682 elderly (17\%) and 3,427 non-elderly (18-64 years) distributed across all provinces, which is representative of the actual distribution of elderly in the population [38]. As shown in Table 1, a higher percent of elderly was observed on the East Coast of Canada and British Columbia as opposed to the other provinces.

When comparing elderly to the general population, significant differences were observed on all characteristics, with the exception of educational level and reported health status; comparable educational levels were noted and perceived health status was reported as good to excellent in both groups. Compared to the general population, a larger number of elderly respondents were men, retired, and had an annual income below Can \$60K. Surprisingly, only 51\% of these seniors indicated having one or more chronic conditions compared to $28 \%$ of the general population. Among the $63 \%$ of elderly reporting self-tracking their health, $18 \%$ did so electronically (digital trackers) compared to $45 \%$ in the general population. The majority of seniors reported tracking their health parameters manually (traditional trackers).

\subsection{Internet and Smart Technologies}

Table 2 shows significant differences between the elderly and the general population in terms of Internet and smart technologies use.

Table 1. Sample characteristics

\begin{tabular}{|c|c|c|c|}
\hline & $\begin{array}{l}\text { Elderly } \\
\text { N }(\%)\end{array}$ & $\begin{array}{c}\text { General } \\
\text { Population } \\
\text { N }(\%)\end{array}$ & $\begin{array}{c}\text { P- } \\
\text { Value }\end{array}$ \\
\hline \multicolumn{4}{|l|}{ Gender } \\
\hline Male & $400(59 \%)$ & $1718(50 \%)$ & \multirow[t]{2}{*}{0.000} \\
\hline Female & $282(41 \%)$ & $1709(50 \%)$ & \\
\hline \multicolumn{4}{|l|}{ Region* } \\
\hline Atlantic provinces & $56(8 \%)$ & $237(7 \%)$ & \multirow{6}{*}{0.000} \\
\hline Quebec & $153(22 \%)$ & $833(24 \%)$ & \\
\hline Ontario & $265(39 \%)$ & $1310(38 \%)$ & \\
\hline Prairies & $37(5 \%)$ & $229(7 \%)$ & \\
\hline Alberta & $50(7 \%)$ & $387(11 \%)$ & \\
\hline British Columbia & $121(18 \%)$ & $431(13 \%)$ & \\
\hline \multicolumn{4}{|l|}{$\begin{array}{l}\text { Highest level of edu- } \\
\text { cation }\end{array}$} \\
\hline $1^{\text {mary }} / 2^{\text {dary }}$ school & $181(27 \%)$ & $758(22 \%)$ & \multirow{4}{*}{0.092} \\
\hline College/CEGEP & $177(26 \%)$ & $972(29 \%)$ & \\
\hline Undergraduate & $207(31 \%)$ & $1093(32 \%)$ & \\
\hline Graduate & $112(16 \%)$ & $549(16 \%)$ & \\
\hline \multicolumn{4}{|l|}{ Employment } \\
\hline Employed FT & $37(5 \%)$ & $1921(56 \%)$ & \multirow{4}{*}{0.000} \\
\hline Employed PT & $44(6 \%)$ & $385(11 \%)$ & \\
\hline Retired & $587(86 \%)$ & $350(10 \%)$ & \\
\hline Other & $14(2 \%)$ & $771(22 \%)$ & \\
\hline \multicolumn{4}{|l|}{ Income } \\
\hline$<\$ 20,000$ & $32(6 \%)$ & $236(8 \%)$ & \multirow{6}{*}{0.000} \\
\hline$\$ 20,000-\$ 39,999$ & $123(22 \%)$ & $461(16 \%)$ & \\
\hline$\$ 40,000-\$ 59,999$ & $131(24 \%)$ & $482(16 \%)$ & \\
\hline$\$ 60,000-\$ 79,999$ & $95(17 \%)$ & $465(16 \%)$ & \\
\hline$\$ 80,000-\$ 99,000$ & $74(13 \%)$ & $424(14 \%)$ & \\
\hline$\geq \$ 100,000$ & $102(18 \%)$ & $863(29 \%)$ & \\
\hline \multicolumn{4}{|l|}{ Chronic conditions } \\
\hline Yes & $342(51 \%)$ & $939(28 \%)$ & \multirow[t]{2}{*}{0.000} \\
\hline No & $323(49 \%)$ & $2413(72 \%)$ & \\
\hline \multicolumn{4}{|l|}{$\begin{array}{l}\text { Perceived health } \\
\text { status }\end{array}$} \\
\hline Very poor/poor & $63(9 \%)$ & $339(10 \%)$ & \multirow{3}{*}{0.866} \\
\hline Good & $346(51 \%)$ & $1724(50 \%)$ & \\
\hline $\begin{array}{l}\text { Very good/ } \\
\text { excellent }\end{array}$ & $274(40 \%)$ & $1364(40 \%)$ & \\
\hline \multicolumn{4}{|l|}{ Self-tracking group } \\
\hline Traditional trackers & $307(45 \%)$ & $744(22 \%)$ & \multirow{3}{*}{0.000} \\
\hline Digital trackers & $121(18 \%)$ & $1547(45 \%)$ & \\
\hline Non trackers & $254(37 \%)$ & $1135(33 \%)$ & \\
\hline $\begin{array}{l}\text { *Atlantic provinces: } \\
\text { foundland and Labra } \\
\text { Manitoba, Saskatchev } \\
\text { from Nunavut, Yukon }\end{array}$ & $\begin{array}{l}\text { ova Scotia, } \\
\text { or, Prince E } \\
\text { an; British C } \\
\text { Northwest ter }\end{array}$ & $\begin{array}{l}\text { Jew Brunswic } \\
\text { lward Island; } \\
\text { olumbia: incl } \\
\text { itories. }\end{array}$ & $\begin{array}{l}\text { New- } \\
\text { rairies: } \\
\text { le data }\end{array}$ \\
\hline
\end{tabular}


$47 \%$ and $50 \%$ of the surveyed elderly reported using a smartphone and a digital tablet, respectively (vs. $84 \%$ and $58 \%$ in the general population). Among those using smartphones/digital tablets, only $20 \%$ downloaded $\geq 1 \mathrm{mApps}$ and $68 \%$ indicated accessing the Internet on a daily basis compared (vs. $46 \%$ and $88 \%$ in the general population, respectively). When asked about smart devices/wearables for health, $83 \%$ of elderly indicated having heard of these technologies, but only $32 \%$ were somewhat or very familiar with them.

Table 2. Elderly Internet and mHealth technologies use compared to the general population

\begin{tabular}{|c|c|c|c|}
\hline & $\begin{array}{l}\text { Elderly } \\
\text { N }(\%)\end{array}$ & $\begin{array}{c}\text { General } \\
\text { Population } \\
\text { N }(\%)\end{array}$ & $\begin{array}{c}\text { P- } \\
\text { Value }\end{array}$ \\
\hline \multicolumn{4}{|l|}{ Use a smartphone } \\
\hline Yes & $323(47 \%)$ & $2887(84 \%)$ & 0.000 \\
\hline No & $359(53 \%)$ & $540(16 \%)$ & \\
\hline \multicolumn{4}{|l|}{ Use a digital tablet } \\
\hline Yes & $340(50 \%)$ & $1997(58 \%)$ & 0.000 \\
\hline No & $343(50 \%)$ & $1429(42 \%)$ & \\
\hline \multicolumn{4}{|l|}{$\begin{array}{l}\text { Access Internet us- } \\
\text { ing smartphone } \\
\text { /tablet }\end{array}$} \\
\hline Never & $52(11 \%)$ & $89(3 \%)$ & 0.000 \\
\hline Less than daily & $97(21 \%)$ & $284(9 \%)$ & \\
\hline On a daily basis & $314(68 \%)$ & $2709(88 \%)$ & \\
\hline \multicolumn{4}{|l|}{$\begin{array}{l}\text { Downloaded } \geq 1 \\
\text { mApps on } \\
\text { smartphone/tablet }\end{array}$} \\
\hline Yes & $91(20 \%)$ & $1406(46 \%)$ & 0.000 \\
\hline No & $372(80 \%)$ & $1676(54 \%)$ & \\
\hline \multicolumn{4}{|l|}{$\begin{array}{l}\text { Heard of smart de- } \\
\text { vices/wearables for } \\
\text { health tracking }\end{array}$} \\
\hline Yes & $383(83 \%)$ & $2667(87 \%)$ & 0.027 \\
\hline No & $80(17 \%)$ & $415(13 \%)$ & \\
\hline \multicolumn{4}{|l|}{$\begin{array}{l}\text { Familiarity with } \\
\text { smart devices/ } \\
\text { wearables for } \\
\text { health }\end{array}$} \\
\hline Slightly familiar & $260(68 \%)$ & $1227(46 \%)$ & 0.000 \\
\hline Somewhat familiar & $103(27 \%)$ & $973(36 \%)$ & \\
\hline Very familiar & $20(5 \%)$ & $467(17 \%)$ & \\
\hline
\end{tabular}

\section{3 mApps for Health and Wellbeing}

Table 3 compares the use of mApps for health/wellbeing between the elderly and the general population. Among the 91 seniors who downloaded $\geq 1$ mApps in the sample (presented in Table 2), 86\% (78 respondents) indicated having used mApps for health/wellbeing in the last three months, which is comparable to the general population $(1,257$ out of 1,406 respondents i.e. $89 \%$ ). No significant differences were noted in relation to the number of mApps for health used between the two groups, nor the extent of data sharing. Interestingly, more elderly reported using these mApps for 1-2 years as compared to the general population ( $38 \%$ vs. $22 \%)$. It is important to note that no significant differences were observed between the elderly and the general population who used mApps for health on the factors that affect their use (i.e. perceived ease of use, perceived usefulness, and expectations confirmation). The overall satisfaction and intention to continue using mApps were favorable in both groups.

\section{Table 3. Use and Perceptions of mApps for Health}

\begin{tabular}{|c|c|c|c|}
\hline & $\begin{array}{l}\text { Elderly } \\
\text { N }(\%)\end{array}$ & $\begin{array}{c}\text { General } \\
\text { Population } \\
\text { N }(\%)\end{array}$ & $\begin{array}{c}\text { P- } \\
\text { Value }\end{array}$ \\
\hline \multicolumn{4}{|l|}{$\begin{array}{l}\text { mApps for health } \\
\text { used (last } 3 \\
\text { months) }\end{array}$} \\
\hline 1 application & $40(51 \%)$ & $514(93 \%)$ & \\
\hline 2 applications & $26(33 \%)$ & $406(32 \%)$ & 0.061 \\
\hline$\geq 3$ applications & $12(15 \%)$ & $337(27 \%)$ & \\
\hline \multicolumn{4}{|l|}{$\begin{array}{l}\text { Duration of use of } \\
\text { mApps for health/ } \\
\text { wellbeing }\end{array}$} \\
\hline$<1$ year & $39(51 \%)$ & $790(65 \%)$ & \\
\hline (1-2) years & $29(38 \%)$ & $269(22 \%)$ & 0.007 \\
\hline$>2$ years & $9(12 \%)$ & $160(13 \%)$ & \\
\hline \multicolumn{4}{|l|}{$\begin{array}{l}\text { Sharing of } \\
\text { health/wellbeing } \\
\text { data from mApps }\end{array}$} \\
\hline Yes & $30(39 \%)$ & $436(35 \%)$ & 0.505 \\
\hline \multirow[t]{2}{*}{ No } & $47(61 \%)$ & $802(65 \%)$ & \\
\hline & $\begin{array}{c}\text { Mean } \\
\text { [Min-Max] }\end{array}$ & $\begin{array}{c}\text { Mean } \\
{[\text { Min-Max] }}\end{array}$ & $\begin{array}{c}\text { P- } \\
\text { Value }\end{array}$ \\
\hline $\begin{array}{l}\text { Satisfaction with } \\
\text { mobile apps }\end{array}$ & $\begin{array}{c}3.79 \\
{[1.67-5]}\end{array}$ & $\begin{array}{c}3.78 \\
{[1-5]}\end{array}$ & 0.895 \\
\hline $\begin{array}{l}\text { Perceived ease of } \\
\text { use }\end{array}$ & $\begin{array}{c}4.00 \\
{[1.5-5]}\end{array}$ & $\begin{array}{l}3.95 \\
{[1-5]}\end{array}$ & 0.549 \\
\hline $\begin{array}{l}\text { Expectations con- } \\
\text { firmation }\end{array}$ & $\begin{array}{c}3.74 \\
{[1.67-5]}\end{array}$ & $\begin{array}{l}3.60 \\
{[1-5]}\end{array}$ & 0.124 \\
\hline $\begin{array}{l}\text { Perceived useful- } \\
\text { ness }\end{array}$ & $\begin{array}{c}3.59 \\
{[1.25-5]}\end{array}$ & $\begin{array}{l}3.56 \\
{[1-5]}\end{array}$ & 0.784 \\
\hline $\begin{array}{l}\text { Intention to con- } \\
\text { tinue using mApps }\end{array}$ & $\begin{array}{c}3.97 \\
{[1-5]} \\
\end{array}$ & $\begin{array}{l}3.91 \\
{[1-5]}\end{array}$ & 0.606 \\
\hline
\end{tabular}

\subsection{Smart Devices/Wearables for Health}

Among the 383 elderly in the sample who have heard of smart devices/wearables (presented in Table 2), $12 \%$ reported having $\geq 1$ smart devices and indicated currently using them; another $9 \%$ reported having these devices but not using them. The majority of the elderly had one device as opposed to the general population with more respondents reporting having two or more devices (see Table 4). 
Table 4. Smart devices/wearables use for health

\begin{tabular}{|c|c|c|c|}
\hline & $\begin{array}{l}\text { Elderly } \\
\text { N (\%) }\end{array}$ & $\begin{array}{c}\text { General } \\
\text { Population } \\
\mathbf{N}(\%) \\
\end{array}$ & $\begin{array}{c}\text { P- } \\
\text { Value }\end{array}$ \\
\hline \multicolumn{4}{|l|}{$\begin{array}{l}\text { Have } \geq 1 \text { smart de- } \\
\text { vice/ wearables for } \\
\text { health }\end{array}$} \\
\hline Yes, use them & $47(12 \%)$ & $533(20 \%)$ & \\
\hline Yes, stopped using & $24(6 \%)$ & $236(9 \%)$ & 0.000 \\
\hline Yes, never used & $11(3 \%)$ & $164(6 \%)$ & \\
\hline No & $302(79 \%)$ & $1734(65 \%)$ & \\
\hline \multicolumn{4}{|l|}{$\begin{array}{l}\text { Number of smart de- } \\
\text { vices/wearables } \\
\text { owned }\end{array}$} \\
\hline $\begin{array}{l}1 \text { device } \\
\geq 2 \text { devices }\end{array}$ & $\begin{array}{c}39(83 \%) \\
8(17 \%)\end{array}$ & $\begin{array}{l}368(69 \%) \\
163(31 \%)\end{array}$ & 0.049 \\
\hline \multicolumn{4}{|l|}{$\begin{array}{l}\text { Duration of smart } \\
\text { devices/wearables use }\end{array}$} \\
\hline$<1$ year & $19(42 \%)$ & $297(56 \%)$ & \\
\hline$(1-2)$ years & $18(40 \%)$ & $153(29 \%)$ & 0.186 \\
\hline$>2$ years & $8(18 \%)$ & $80(15 \%)$ & \\
\hline \multicolumn{4}{|l|}{$\begin{array}{l}\text { Smart devices/weara- } \\
\text { bles use in partner- } \\
\text { ship with healthcare } \\
\text { provider }\end{array}$} \\
\hline Yes & $3(6 \%)$ & $73(14 \%)$ & 0.167 \\
\hline No & $43(93 \%)$ & $460(86 \%)$ & \\
\hline & $\begin{array}{l}\text { Mean } \\
\text { [Min- } \\
\text { Max] }\end{array}$ & $\begin{array}{c}\text { Mean } \\
{[\text { Min-Max] }}\end{array}$ & $\begin{array}{c}\text { P- } \\
\text { Value }\end{array}$ \\
\hline $\begin{array}{l}\text { Satisfaction with smart } \\
\text { devices/ } \\
\text { wearables }\end{array}$ & $\begin{array}{l}4.08 \\
{[2-5]}\end{array}$ & $\begin{array}{l}4.07 \\
{[1-5]}\end{array}$ & 0.980 \\
\hline Perceived ease of use & $\begin{array}{l}4.20 \\
{[2-5]}\end{array}$ & $\begin{array}{l}4.21 \\
{[1-5]}\end{array}$ & 0.921 \\
\hline $\begin{array}{l}\text { Expectations confir- } \\
\text { mation }\end{array}$ & $\begin{array}{c}3.78 \\
{[1.67-5]}\end{array}$ & $\begin{array}{l}3.89 \\
{[1-5]}\end{array}$ & 0.313 \\
\hline Perceived usefulness & $\begin{array}{c}3.66 \\
{[1.50-5]}\end{array}$ & $\begin{array}{c}3.82 \\
{[1-5]}\end{array}$ & 0.152 \\
\hline $\begin{array}{l}\text { Intention to continue } \\
\text { using smart de- } \\
\text { vices/wearables }\end{array}$ & $\begin{array}{l}4.22 \\
{[1-5]}\end{array}$ & $\begin{array}{l}4.26 \\
{[1-5]} \\
\end{array}$ & 0.751 \\
\hline
\end{tabular}

When asked about the types of devices used, the answers also varied between the two groups. The most commonly reported devices were bracelets/ wristbands (5.6\% vs. $13.6 \%$ for elderly and the general population, respectively). Both groups who reported using smart devices/wearables did not differ significantly in relation to the duration of use of these technologies and the extent of use in partnership with a health care provider, which was relatively low among respondents in both groups (6\% for elderly and $14 \%$ for the general population). It is important to note that no significant differences were observed between the elderly and the general population who use smart devices/wearables on the factors that affect their use (i.e. perceived ease of use, perceived usefulness, and expectations confirmation). The overall satisfaction with and the intention to continue using these smart devices/wearables were high. Elderly who use wearables and smart devices reported being very satisfied (mean=4.1 on a 5-point Likert scale), perceived their devices to be user-friendly (mean $=4.2$ ), and had a firm intention to continue using them in the future (mean=4.2).

Importantly, respondents perceive these devices as relatively useful. About 6 out of 10 users said that they have maintained or improved their health status by using digital self-tracking connected devices. A majority of users $(66 \%)$ reported they were more informed or more knowledgeable about their health condition. More than half $(53 \%)$ of users said they felt more confident taking care of their health or more autonomous in the management of their condition. On the other hand, feeling less anxious about one's own health and having more informed discussions with a doctor were not perceived as major benefits among the elderly group.

\subsection{Appreciation of Smart Devices and Self- tracking Behaviors among Seniors}

Cronbach alpha was used to assess the reliability of the measures included in this study. The results (see Table 5) show that all the measures exceed the 0.70 threshold of statistical significance [31]. The validity of the variables included was also supported; the square root of the variance shared by each variable and its respective items (diagonal) is greater than the inter-correlations between the variables.

\section{Table 5. Variance shared by variables}

\begin{tabular}{|c|c|c|c|c|c|c|c|}
\hline & $\begin{array}{c}\text { \# of } \\
\text { items }\end{array}$ & $\alpha$ & PU & $\begin{array}{l}\text { PE } \\
\text { OU }\end{array}$ & EC & US & IC \\
\hline $\begin{array}{l}\text { Perceived } \\
\text { usefulness } \\
\text { (PU) }\end{array}$ & 4 & .86 & .82 & $.42 *$ & $.79 *$ & $.70 *$ & $.71 *$ \\
\hline $\begin{array}{l}\text { Perceived } \\
\text { ease of use } \\
\text { (PEOU) }\end{array}$ & 4 & .88 & - & .84 & $.65^{*}$ & $.62 *$ & $.45^{*}$ \\
\hline $\begin{array}{l}\text { Confirma- } \\
\text { tion } \\
\text { of expecta- } \\
\text { tions (EC) }\end{array}$ & 3 & .70 & - & - & .83 & $.78 *$ & $.63 *$ \\
\hline $\begin{array}{l}\text { User } \\
\text { satisfaction } \\
\text { (US) }\end{array}$ & 3 & .88 & - & - & - & .89 & $.74 *$ \\
\hline $\begin{array}{l}\text { Intention } \\
\text { to continue } \\
\text { usage (IC) }\end{array}$ & 3 & .93 & - & - & - & - & .90 \\
\hline${ }^{*} \mathrm{p}<.01 ; \alpha:$ & onbach & Ipha. & & & & & \\
\hline
\end{tabular}

PLS regression analyses that were performed to test the links in the model (see Figure 1) show that all rela- 
tionships but one were supported, and the model explained $60 \%$ of the variance in the dependent variable. These results indicate that expectations confirmation is strongly related to ease of use, perceived usefulness, and user satisfaction.

Last, a multinomial logistic regression including sociodemographic and health status variables was performed to calculate odds ratios (OR) describing the odds of tracking one's own health using traditional or digital devices compared with the odds of non-tracking (reference category) among the elderly group. The traditional 0.05 criterion of statistical significance was employed for all tests. Addition of the predictors to a model that contained only the intercept significantly improved the fit between model and data; $\chi^{2}{ }_{34}(\mathrm{~N}=682)=49.46$, Nagelkerke $R^{2}=0.11, p<.01$. As indicated in Table 6, our analyses determined no statistically significant differences between groups in terms of gender, educational level, occupation, and perceived health condition. However, significant differences were observed in terms of region and chronic conditions. First, elderly living in the province of Alberta were 4.9 times more likely to be in the digital self-tracking group than elderly living in other Canadian regions. Second, compared with elderly living with no chronic condition, chronic patients were 0.4 times less likely to be digital self-trackers.

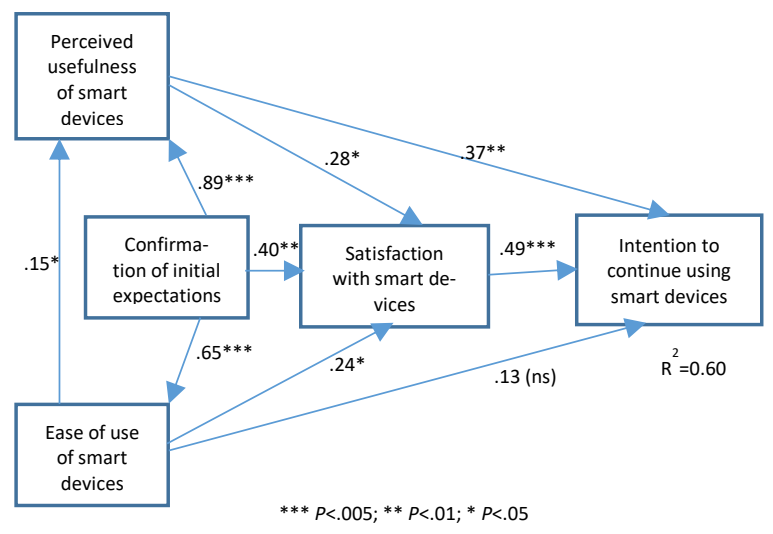

Figure 1. PLS Results

\section{Discussion}

This study investigates elderly Canadians' use of mHealth technologies in comparison to the general population, and assesses the pattern of use of these technologies for self-tracking purposes. The surveyed elderly population differed significantly from the general population in relation to socio-demographic variables. Hence the importance of having a closer examination of seniors' use of mHealth technologies for self-tracking purposes compared to the general population, which can inform future research, practice and policy efforts in this area.

\section{Table 6. Multinomial logistic regression results*}

\begin{tabular}{|c|c|c|c|c|c|c|}
\hline \multirow[t]{2}{*}{$\begin{array}{l}\text { Charac- } \\
\text { teristics }\end{array}$} & \multicolumn{3}{|c|}{$\begin{array}{c}\text { Traditional } \\
\text { trackers } \\
(n=307)\end{array}$} & \multicolumn{3}{|c|}{$\begin{array}{c}\text { Digital } \\
\text { trackers } \\
(n=121)\end{array}$} \\
\hline & OR & $.95 \mathrm{CI}$ & Sig. & OR & $.95 \mathrm{CI}$ & Sig. \\
\hline Intercept & - & - & $<.001$ & - & - & $<.001$ \\
\hline $\begin{array}{l}\text { Gender } \\
\text { Female }\end{array}$ & 1.176 & $\begin{array}{c}0.761- \\
1.817\end{array}$ & .466 & 1.144 & $\begin{array}{l}0.656- \\
1.996\end{array}$ & .635 \\
\hline \multicolumn{7}{|l|}{ Region } \\
\hline $\begin{array}{l}\text { Atlantic } \\
\text { provinces }\end{array}$ & 1.342 & $\begin{array}{c}0.582- \\
3.094\end{array}$ & .490 & 1.098 & $\begin{array}{l}0.379- \\
3.183\end{array}$ & .864 \\
\hline Quebec & 1.896 & $\begin{array}{l}0.983- \\
3.658\end{array}$ & .056 & 1.322 & $\begin{array}{l}0.585- \\
2.988\end{array}$ & .502 \\
\hline Ontario & 1.503 & $\begin{array}{l}0.828- \\
2.729\end{array}$ & .181 & 1.001 & $\begin{array}{l}0.478- \\
2.096\end{array}$ & .997 \\
\hline Prairies & 1.270 & $\begin{array}{l}0.487- \\
3.309\end{array}$ & .625 & 0.793 & $\begin{array}{l}0.220- \\
2.861\end{array}$ & .723 \\
\hline Alberta & 6.053 & $\begin{array}{l}1.719- \\
21.312\end{array}$ & .005 & 4.914 & $\begin{array}{l}1.221- \\
19.775\end{array}$ & .025 \\
\hline \multicolumn{7}{|c|}{ Education level } \\
\hline $\begin{array}{l}1^{\text {mary }} / 2^{\text {dary }} \\
\text { school }\end{array}$ & 1.064 & $\begin{array}{l}0.539- \\
2.102\end{array}$ & .665 & 0.623 & $\begin{array}{c}0.274- \\
1.616\end{array}$ & .368 \\
\hline $\begin{array}{l}\text { College/ } \\
\text { CEGEP }\end{array}$ & 1.371 & $\begin{array}{l}0.686- \\
2.738\end{array}$ & .265 & 0.623 & $\begin{array}{l}0.541- \\
2.960\end{array}$ & .588 \\
\hline $\begin{array}{l}\text { University } \\
\text { (under- } \\
\text { grad) }\end{array}$ & 1.270 & $\begin{array}{l}0.675- \\
2.392\end{array}$ & .236 & 0.832 & $\begin{array}{l}.571- \\
2.675\end{array}$ & .590 \\
\hline \multicolumn{7}{|c|}{ Occupation } \\
\hline $\begin{array}{l}\text { Employed } \\
\text { full-time }\end{array}$ & 1.078 & $\begin{array}{l}0.181- \\
6.422\end{array}$ & .935 & .663 & $\begin{array}{l}0.099- \\
4.438\end{array}$ & .672 \\
\hline $\begin{array}{l}\text { Employed } \\
\text { part-time }\end{array}$ & 1.972 & $\begin{array}{l}0.342- \\
11.375\end{array}$ & .447 & .799 & $\begin{array}{l}0.118- \\
5.404\end{array}$ & .818 \\
\hline Retired & 1.596 & $\begin{array}{l}0.333- \\
7.649\end{array}$ & .559 & .699 & $\begin{array}{l}.139- \\
3.525\end{array}$ & .664 \\
\hline \multicolumn{7}{|c|}{$\begin{array}{l}\text { Perceived health } \\
\text { condition }\end{array}$} \\
\hline $\begin{array}{l}\text { Very } \\
\text { poor/ poor }\end{array}$ & 0.524 & $\begin{array}{c}0.240- \\
1.144\end{array}$ & .104 & 0.734 & $\begin{array}{c}0.275- \\
1.955\end{array}$ & .536 \\
\hline $\begin{array}{l}\text { Fair or } \\
\text { good }\end{array}$ & 1.094 & $\begin{array}{l}.692- \\
1.730\end{array}$ & .699 & 1.249 & $\begin{array}{l}0.697- \\
2.240\end{array}$ & .455 \\
\hline \multicolumn{7}{|c|}{ Chronic disease(s) } \\
\hline $\begin{array}{l}\text { Has } \geq 1 \\
\text { chronic } \\
\text { disease(s) }\end{array}$ & 0.439 & $\begin{array}{l}0.281- \\
0.686\end{array}$ & $<.001$ & 0.431 & $\begin{array}{l}0.245- \\
0.758\end{array}$ & $<.005$ \\
\hline $\begin{array}{l}* \text { Reference } \\
\text { Legend: OR }\end{array}$ & $\begin{array}{l}\text { ategory } \\
\text { Odds R }\end{array}$ & $\begin{array}{l}\text { non tracl } \\
\text { io; } \mathrm{CI}=\mathrm{C}\end{array}$ & $s(n=2$ & terval. & & \\
\hline
\end{tabular}

Although there were significant differences between the elderly and the general population on Internet and smart technologies use, around half of the sample 65 years and older reported using either a smartphone or a digital tablet, and $70 \%$ indicated accessing the Internet on a daily basis. So the ability to use these devices and connecting to the Internet is no longer a key challenge. A large number of Canadian seniors in the community have already acquired these technologies, which presents an opportunity to leverage 
them, beyond basic communication use, to support their wellbeing by enhancing social connectedness and improving the management of their health conditions $[12,30]$.

Despite the comparable reported good to excellent health status among seniors and the general population, the prevalence of chronic conditions was significantly higher among the elderly group (51\%), which necessitates close monitoring and management of their health. Therefore, it is important to leverage existing technologies that can support their health and wellbeing needs in the community, and potentially connect them with caregivers and health care providers. This is particularly relevant in relation to wearables (e.g., wristbands, pedometers, etc.) and mApps that allow users to store and monitor health-related data. Prior research discussed the important role of technology to support the ability of elderly to remain at home, improve their quality of life, and enhance family caregivers' and health care professionals' access to relevant information $[10,25]$. This is in line with the findings of this study that showed a high satisfaction rate with mHealth technologies and favorable conditions for their use. With a growing elderly population in Canada and an increasing prevalence of chornic conditions among seniors, it is essential to consider innovative technological solutions that would support their health care needs.

Nevertheless, this study demonstrates that the potential of mHealth technologies for self-tracking purposes has not been fully captured yet in the context of seniors. Although $63 \%$ of elderly reported tracking their health measures, the majority did so manually, which may compromise the process given the risk of losing information and the difficulty in sharing it with health care providers and caregivers. This considerable number of elderly tracking their health measures is indicative of the need and interest among this group to monitor their health. Therefore, it is critical to develop strategies to enhance their awareness and knowledge of existing mHealth technologies available at their disposal, and how to use them, and encourage family physicians and allied health professionals to communicate about these options with them. In addition, it is equally important to understand seniors' priorities and self-tracking needs in order to offer technologies suitable to address these needs [6]. This is particularly relevant in light of recent studies in other countries showing that seniors' acceptance of mApps can be improved by informing them about the potential benefits of these technologies [41], and that seniors agree to share collected data through in-home monitoring and sensors with professional caregivers and demand participation in decisions about technology [9].
Interestingly, the majority of the mApps downloaded by the surveyed elderly consisted of applications used for health and wellbeing. Around half of the elderly who used mApps in the past three months used two or more of these applications. This is indicative of perceived benefits of these technologies by seniors, as also reflected in the sustained use of these mApps over time. Once they start using mApps for health, seniors' interest and willingness to use more than one mApp over a long period of time was confirmed (Table 3, higher percent reporting > 1year use compared to the general population). Future studies should investigate the motivation and factors that facilitate their embracement of mHealth technologies to develop strategies that would enable a broader range of elderly to benefit from them. Nevertheless, it is important to note that a low and comparable percent of respondents, among the elderly and in the general population $(39 \%$ and $35 \%$ respectively), indicated either sharing data from mApps or using smart devices/wearables in partnership with healthcare providers. This reflects a disconnect between the actual needs and willingness of the elderly in the community to use mHealth technologies, and the ability and readiness of health care providers to leverage these tools to support the care provided for these individuals.

The PLS regression analyses confirmed that expectations confirmation is strongly related to ease of use, perceived usefulness, and user satisfaction. Hence, it is critical to adequately manage seniors' initial expectations to ensure greater adherence and continued usage of wearables and smart devices. These initial expectations may be considered as the anchor for the subsequent behavior of seniors and their acceptance and use of these technologies, and may be shaped by the environment in which they live. Caregivers and family members, peers, as well as health care providers, play a significant role in shaping these initial expectations and the subsequent benefit that seniors may reap out of using these devices. Interestingly, we found that seniors living in Alberta were 4.9 times more likely to be in the digital self-tracking group compared to seniors in other regions. Alberta is recognized to attract young families and is known for its highest rate of workforce growth. This may have implications for seniors living in this province who are surrounded by a younger population heavily immersed in technology, and which may have expectations in relation to leveraging technology to care for their elderly.

A culture shift in the provision of care to the elderly living in the community is deemed necessary in Canada to keep up with the development of mHealth technologies and the changing demographics and expectations of patients and their caregivers. This is particularly important in light of the results of this study 
that show that elderly living with chronic conditions are 0.4 times less likely to be digital self-trackers. This is considered a "missed opportunity" at the community level as the individuals who may benefit most from mHealth technologies (i.e. elderly with chronic conditions) do not seem to be actually using them. The question remains: How can we make this leap and paradigm shift? Evidently, this shift cannot come along without paralleled changes at the Canadian health system level, in relation to existing policies, reimbursement modalities, and the structure of health care services delivery. In order to optimize the use of mHealth technologies to support elderly in the community, it is important that health care providers integrate data gathered through these smart devices in the delivery of care services.

This shift also requires changes at the system level. We are beginning to witness some of these changes in some Canadian provinces with initiatives allowing patients to leverage wearables and smart devices to support their health. Alberta has recently released a personal health record (PHR) initiative allowing patients to collect and store their own health data using wearables and smart medical devices, and manage authorizations for accessing these data. Other provinces, including Quebec, Nova Scotia and Saskatchewan, are following this lead with health information portals giving patients more access and control over their health data. These initiatives have to be paralleled, however with changes at the policy and reimbursement levels to close the loop and encourage health care providers to endorse these new technologies as essential components in the delivery of health services and enablers for better quality of care.

The consistent high satisfaction of the elderly with mApps and smart devices/wearables, and their intention to continue using them is a positive indication of the evolving expectations of the Canadian elderly population, and a potential catalyst for change. The results of this study confirm that, once mApps and smart devices/wearables are used, the perceived ease of use and usefulness of these technologies do not vary by age of users. As the elderly population continues to grow with members of the current workforce, who may be using technology on a daily basis today (e.g., mApps and smart devices), going into retirement, the demand for more connectedness with health care providers and better response from the health care system in a networked society will likely increase.

This study presents major contributions to an under-researched area on elderly and mHealth technologies use. The findings are a first step towards understanding the behaviors and attitudes of seniors toward these technologies. By unveiling the actual prevalence of mHealth technologies use among the elderly in the Canadian population, and exploring their familiarity and satisfaction with these technologies, we set the stage for future research to investigate the optimal environment and predictors for effective use [36] of these technologies.

Before we conclude, it is important to note some limitations associated with the study design and breadth of data. For one thing, it must be acknowledged that the data set used in the present study is from a single country, limiting the generalizability of the findings. Further, the cross-sectional nature of the survey precludes a full assessment of the predictors of the elderly use of mHealth technologies, as well as an evaluation of the variation of their behaviors over time, especially with changes in their health conditions. Last, given the exploratory nature of the study and the focus on mApps and smart devices/wearables, limited data were collected on the functional ability of the elderly, their level of independence and/or illness, and other sociodemographic characteristics that may play a role in shaping the use of these technologies. Future studies should take these factors into account to better understand the variation in the use of mHealth technologies by seniors in the community (e.g., digital divide), and determine the optimal conditions in which these technologies can best benefit them.

\section{Conclusions}

We live in a world of connectivity in which a wealth of data is generated on a daily basis. Seniors represent a major group in our society, which is most vulnerable, needs continuous care and attention, and consumes most health care resources. Hence the potential for technology in general, and mHealth technologies in particular, to support their health and wellbeing must be investigated. This study shows that, despite the differences between the elderly and the general population in Canada in relation to mHealth technologies, a considerable number of elderly in the community are familiar with and use these technologies. Importantly, elderly who use mHealth technologies are highly satisfied with them and plan to continue using them in the future. Understanding why senior citizens who are familiar with mHealth technologies are not using them would inform future work in this area. Last, leveraging these technologies in partnership with family physicians and allied health care professionals, and sharing of generated health and wellbeing data with them remains very limited as of today. As mentioned earlier, the current development and deployment of various PHR initiatives in Canada appear as a promising approach to facilitate bidirectional health information 
exchanges between providers and patients, including seniors.

\section{References}

[1] Accenture Consulting, "Patients want a heavy dose of digital", Accenture., 2016. https://www.accenture.com/us-en/insight-research-shows-patients-unitedstates-want-heavy

[2] Bhattacherjee, A., "Understanding Information Systems Continuance: An Expectation-Confirmation Model", MIS Quarterly 25(3), 2001, pp. 351.

[3] Bloom, D.E., "7 Billion and Counting", Science 333(6042), 2011, pp. 562-569.

[4] Bowling, A., "Just one question: If one question works, why ask several?", Journal of Epidemiology and Community Health 59(5), 2005, pp. 342-345.

[5] Brown, B., “Saleforce's 2016 Connected Patient Report: insights into patient preferences on telemedicine, wearables and post-discharge care", Health Tech Insider, 2016.

https://healthtechinsider.com/2016/08/25/2016-connected-patient-report/

[6] Caldeira, C., and Y. Chen, "Seniors and Self-tracking Technology.", In Perspectives on human-computer interaction research with older people. Springer Berlin Heidelberg, New York, NY, 2019.

[7] Canadian Institute for Health Information, Health care in Canada, 2011 a focus on seniors and aging, Canadian Institute for Health Information, Ottawa, Ont., 2012.

[8] Canadian Institute for Health Information, How Canada Compares: Results From The Commonwealth Fund's 2016 International Health Policy Survey of Adults in 11 Countries - Accessible Report., CIHI, Ottawa, Ont., 2017.

[9] Claes, V., E. Devriendt, J. Tournoy, and K. Milisen, "Attitudes and perceptions of adults of 60 years and older towards in-home monitoring of the activities of daily living with contactless sensors: An explorative study", International Journal of Nursing Studies 52(1), 2015, pp. 134-148.

[10] Czaja, S.J., "Long-term care services and support systems for older adults: The role of technology.", American Psychologist 71(4), 2016, pp. 294-301.
[11] Davis, F.D., "Perceived Usefulness, Perceived Ease of Use, and User Acceptance of Information Technology”, MIS Quarterly 13(3), 1989, pp. 319.

[12] Fischer, S.H., D. David, B.H. Crotty, M. Dierks, and C. Safran, "Acceptance and use of health information technology by community-dwelling elders", International Journal of Medical Informatics 83(9), 2014, pp. 624-635.

[13] Fox, S., The Self-Tracking Data Explosion, Pew Research Center, Washington, D.C., 2013.

[14] GBD 2016 Disease and Injury Incidence and Prevalence Collaborators., "Global, regional, and national incidence, prevalence, and years lived with disability for 328 diseases and injuries for 195 countries, 1990-2016: a systematic analysis for the Global Burden of Disease Study 2016", The Lancet 390(10100), 2017, pp. 1211-1259.

[15] Global GFK, "Health and Fitness tracking”, GFK, 2019. https://www.gfk.com/global-studies/global-studies-fitness-tracking/

[16] Grindrod, K., A. Moen, J.S. Ancker, et al., "“You Get Reminded You're a Sick Person': Personal Data Tracking and Patients With Multiple Chronic Conditions", Journal of Medical Internet Research 17(8), 2015, pp. e202.

[17] Heinz, M., P. Martin, J.A. Margrett, et al., "Perceptions of Technology among Older Adults", Journal of Gerontological Nursing 39(1), 2013, pp. 42-51.

[18] Hong, S., J.Y.L. Thong, and K.Y. Tam, "Understanding continued information technology usage behavior: A comparison of three models in the context of mobile internet", Decision Support Systems 42(3), 2006, pp. 1819-1834.

[19] IFOP, “Objets connectes et usage des donnees: la perception des Francais", 2015. http://www.ifop.fr/media/poll/3250-1-study_file.pdf

[20] Jaana, M., and G. Paré, "Home telemonitoring of patients with diabetes: a systematic assessment of observed effects", Journal of Evaluation in Clinical Practice 13(2), 2007, pp. 242-253.

[21] Jaana, M., G. Paré, and C. Sicotte, "Hypertension Home Telemonitoring: Current Evidence and Recommendations for Future Studies", Disease Management \& Health Outcomes 15(1), 2007, pp. 19-31. 
[22] Jaana, M., G. Paré, and C. Sicotte, "Home telemonitoring for respiratory conditions: a systematic review", The American Journal of Managed Care 15(5), 2009, pp. 313-320.

[23] Jaana, M., and H. Sherrard, "Rural-Urban Comparison of Telehome Monitoring for Patients with Chronic Heart Failure", Telemedicine and e-Health, 2018.

[24] Jaana, M., H. Sherrard, and G. Paré, “A prospective evaluation of telemonitoring use by seniors with chronic heart failure: Adoption, self-care, and empowerment", Health Informatics Journal, 2018, pp. 146045821879945 .

[25] Khosravi, P., and A.H. Ghapanchi, "Investigating the effectiveness of technologies applied to assist seniors: A systematic literature review", International Journal of Medical Informatics 85(1), 2016, pp. 17-26.

[26] Kitsiou, S., G. Paré, M. Jaana, and B. Gerber, “Effectiveness of mHealth interventions for patients with diabetes: An overview of systematic reviews", PLOS ONE 12(3), 2017, pp. e0173160.

[27] Lupton, D., "Self-tracking, health and medicine", Health Sociology Review 26(1), 2017, pp. 1-5.

[28] McMahon, S.K., B. Lewis, M. Oakes, W. Guan, J.F. Wyman, and A.J. Rothman, “Older Adults' Experiences Using a Commercially Available Monitor to Self-Track Their Physical Activity", JMIR mHealth and uHealth 4(2), 2016, pp. e35.

[29] McMurtrey, M.E., S.M. Zeltmann, J.P. Downey, and R.E. McGaughey, "Seniors and technology: results from a field study", Journal of Computer Information Systems 51(4), 2011, pp. 22-30.

[30] Morris, M.E., B. Adair, E. Ozanne, et al., "Smart technologies to enhance social connectedness in older people who live at home: Smart technology and social connectedness", Australasian Journal on Ageing 33(3), 2014, pp. 142-152.

[31] Nunnally, J., Psychometric theory., McGraw-Hill, New York, NY, 1978.

[32] Oliver, R.L., "A Cognitive Model of the Antecedents and Consequences of Satisfaction Decisions", Journal of Marketing Research 17(4), 1980, pp. 460.
[33] Osborn, R., M.M. Doty, D. Moulds, D.O. Sarnak, and A. Shah, "Older Americans Were Sicker And Faced More Financial Barriers To Health Care Than Counterparts In Other Countries", Health Affairs 36(12), 2017, pp. 2123-2132.

[34] Paré, G., M. Jaana, and C. Sicotte, "Systematic Review of Home Telemonitoring for Chronic Diseases: The Evidence Base", Journal of the American Medical Informatics Association 14(3), 2007, pp. 269-277.

[35] Paré, G., C. Leaver, and C. Bourget, "Diffusion of the Digital Health Self-Tracking Movement in Canada: Results of a National Survey", Journal of Medical Internet Research 20(5), 2018, e177.

[36] Savoli, A., H. Barki, and G. Paré, "Examining How Chronically Ill Patients' Reactions to, and Effective Use of Information Technology Can Influence How Well They Self-Manage their Illness", MIS Quarterly, (forthcoming).

[37] Seifert, A., A. Schlomann, C. Rietz, and H.R. Schelling, "The use of mobile devices for physical activity tracking in older adults' everyday life", Digital Health 3, 2017, pp. 2055207617740088.

[38] Statistics Canada, “The Daily - Canada's population estimates: Age and sex, July 1, 2018”, statcan.gc.ca, 2019.

https://www150.statcan.gc.ca/n1/daily-quotidien/190125/dq190125a-eng.htm

[39] The Commonwealth Fund, "2017 Commonwealth Fund International Health Policy Survey of Older Adults in 11 Countries", The Commonwealth Fund, 2017. https://www.commonwealthfund.org/publications/infographic/2017/dec/2017-commonwealth-fundinternational-health-policy-survey-older

[40] United Nations, "World population ageing 2017”, Department of Economic and Social Affairs Population Division, 2017.

[41] de Veer, A.J., J.M. Peeters, A.E. Brabers, F.G. Schellevis, J.J.J. Rademakers, and A.L. Francke, "Determinants of the intention to use e-Health by community dwelling older people", BMC health services research 15(1), 2015, pp. 103. 